\title{
Acute Stress Disorder
}

National Cancer Institute

\section{Source}

National Cancer Institute. Acute Stress Disorder. NCI Thesaurus. Code C92621.

An anxiety disorder precipitated by an experience of intense fear or horror while exposed to a traumatic (especially life-threatening) event. The disorder is characterized by dissociative symptoms; vivid recollections of the traumatic event; avoidance of stimuli associated with the traumatic event; and a constant state of hyperarousal for no more than one month. 